\title{
MANIFESTAÇÕES PATOLÓGICAS EM DECORRÊNCIA DO MAU FUNCIONAMENTO DO SISTEMA DE JUNTAS DE DILATAÇÃO EM OAES: ESTUDO DE CASO
}

\author{
PEREIRA, RODRIGO \\ Engenheiro Civil \\ Strata Engenharia Ltda. \\ Minas Gerais; Brasil \\ rodrigoestruturas@gmail.com \\ DE ALENCAR, CECÍLIA NARDI \\ Estudante \\ Universidade Federal de Minas Gerais \\ Minas Gerais; Brasil \\ cecilia.nardi@hotmail.com
}

\author{
MARTINS, VITOR ARAÚJO \\ Engenheiro \\ Strata Engenharia Ltda. \\ Minas Gerais; Brasil \\ vitoraraujomartins@outlook.com
DO CARMO, ANNE KAROLINE FORTUNATO
Engenheira Civil
Pontifícia Universidade Católica de Minas Gerais
Minas Gerais; Brasil
annekarolinefc@gmail.com

\section{RESUMO}

As juntas de dilatação são elementos que constituem uma separação física entre dois elementos estruturais ou estruturais e não estruturais, de forma a permitir a movimentação entre os mesmos sem que haja transferência das solicitações. Por muitas vezes, o mau funcionamento do sistema de juntas acarreta na percolação de águas na estrutura, além de causar o desconforto aos usuários por meio de desníveis e fissuras no pavimento. Os principais problemas decorrem de falhas na execução e ausência ou inadequação da manutenção. Sabe-se que as juntas de dilatação possuem uma vida útil inferior quando comparada aos demais elementos de uma ponte. Nesse contexto, as inspeções rotineiras mostram-se de fundamental importância para a elevação da vida útil e redução dos custos de intervenções. Nesse trabalho, será realizado o estudo de caso sobre o sistema de juntas de dilatação de três Pontes, de forma a analisar e evidenciar as principais manifestações patológicas.

Palavras-chave: Juntas de dilatação, pontes, viadutos, manifestações patológicas.

\section{ABSTRACT}

Expansion joints are elements that constitute a physical separation between two structural or structural and nonstructural elements, in order to allow movement between them without transfer of requesting efforts. Malfunctioning of the joint system often results in percolating water to the mesostructure, superstructure, and encounters, as well as causing discomfort to users through unevenness and cracks in the pavement. The main problems stem from failures in execution and lack or inadequate maintenance. Expansion joints are known to have a shorter service life compared to the other elements of a bridge. In this context, routine inspections are of fundamental importance for increasing the useful life and reducing intervention costs. In this work, a case study will be carried out on the three bridge dilatation joint system, in order to analyze the main pathological manifestations.

Keywords: Bridge dilatation joint system, expansion joints, bridge, pathologies.

\section{INTRODUÇÃO}

Juntas de dilatação são elementos que constituem intervalos abertos, permitindo a movimentação entre duas estruturas, de forma com que não haja transmissão de esforços entre ambas. Com exceção das juntas abertas, esses intervalos são preenchidos por variados dispositivos, de diferentes materiais, como elastômeros e placas metálicas (DNIT 092 - ES, 2006).

De acordo com Ferreira (2013), as primeiras juntas de dilatação foram utilizadas em pontes ferroviárias metálicas. Por razões de segurança, criou-se a necessidade de preencher o espaço das juntas, sendo inicialmente utilizadas placas de cobertura e juntas de chapas deslizantes. Entretanto, tais métodos não conferiam impermeabilidade, característica que encorporou o sistema de juntas apenas com o início da utilização de placas de metal envolvidas em borracha. Tal método resultou no desenvolvimento de diferentes tipos de juntas de dilatação, conforme Figura 1 abaixo. 


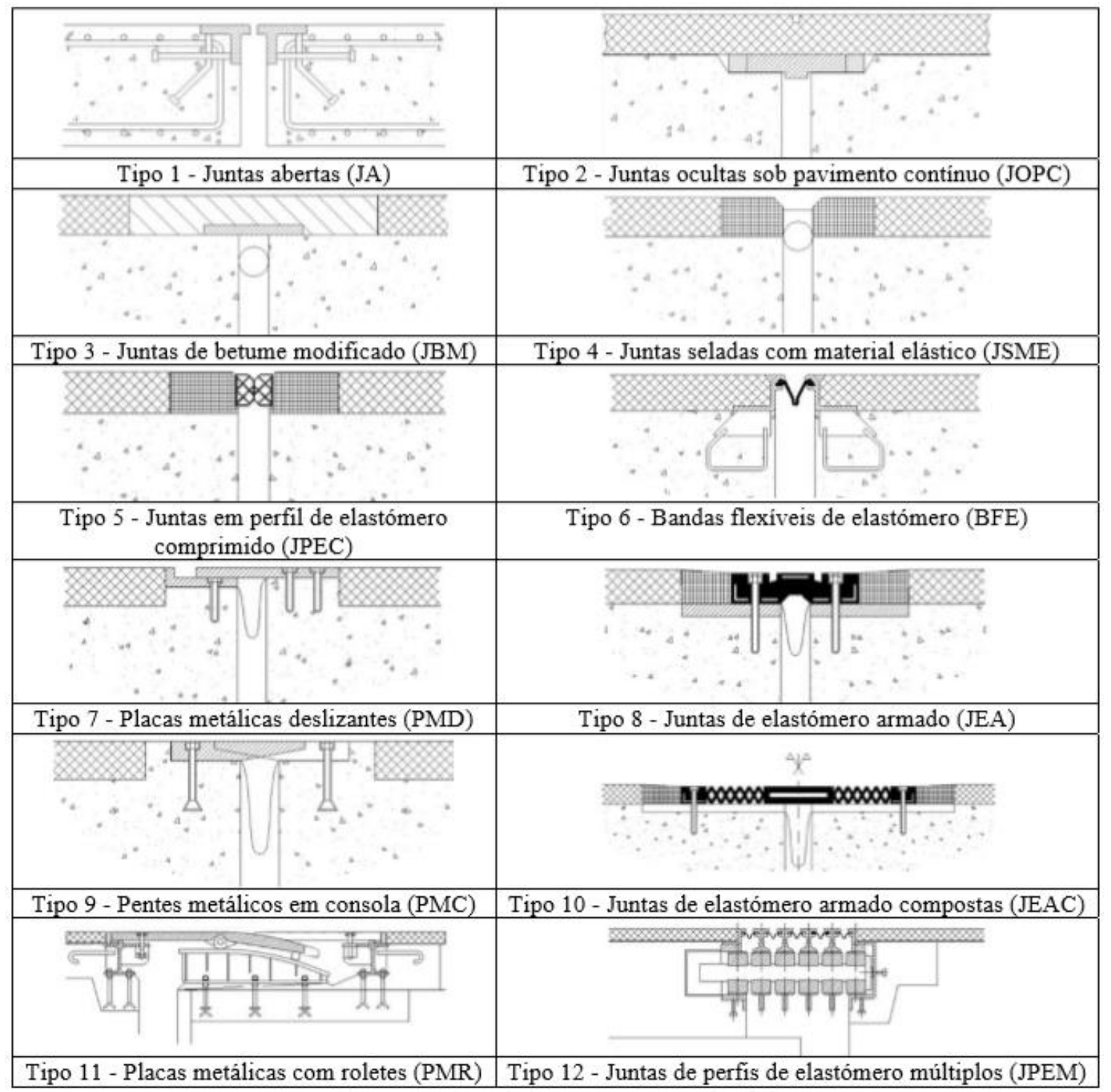

Figura 1: Tipos de juntas - Esquemas tipo (LIMA, BRITO, 2009).

De acordo com Ramos (2017), a vida útil das juntas de dilatação é menor que dos demais elementos das Obras de Arte Especiais (OAEs). Além das possíveis falhas de estanqueidade, o elemento está sujeito ao desgaste contínuo e a fortes impactos decorrentes do contato repetitivo com cargas móveis. Dessa maneira, torna-se necessário maior frequência quanto às intervenções, resultando em um aumento significativo no custo da obra ao longo de sua vida em serviço (MISTRY, 2005).

$\mathrm{O}$ artigo encontra-se dividido em capítulos, sendo o primeiro uma breve introdução sobre juntas de dilatação e suas características. O segundo capítulo é divido em seções, onde serão expostas as determinações normativas, manifestações patológicas mais frequentes nas juntas de pontes e viadutos, métodos de inspeção e alternativas para inutilização de juntas de dilatação. No terceiro capítulo será realizado o estudo de caso de 3 pontes rodoviárias brasileiras que apresentam patologias no sistema de juntas. No quarto e último capítulo será feito a conclusão do artigo.

\section{DESENVOLVIMENTO}

\subsection{Metodologia}

Embora as juntas de dilatação estejam presentes em grande parte das OAEs brasileiras e que sejam fonte de frequentes problemas e gastos com intervenção para os órgãos responsáveis, não há grande volume de pesquisas destinadas aos seus tipos e danos associados. Dessa maneira, buscou-se auxílio na bibliografia americana e portuguesa sobre o assunto, de forma a complementar as tratativas realizadas pelas referências normativas brasileiras. 
Na sequência, diante de um grande acervo de relatórios de inspeções realizadas, selecionou-se casos em que as juntas de dilatação apresentassem patologias clássicas do dispositivo, em estágios avançados e que permitissem destacar tanto a sua deterioração natural quanto a parcela consequente às práticas indevidas na execução.

\subsection{Revisão bibliográfica}

\subsubsection{Determinações normativas}

Visando o conforto do usuário a Norma DNIT 092 - ES (2006) determina que a transição entre a ponte e os acessos, ou demais subdivisões, deve ser realizada de forma suave. Além disso, o espaço existente deve ser suficiente para permitir movimentos de expansão, mas não exagerado, uma vez que aberturas mal projetadas são perigosas e desconfortáveis para o tráfego, além de resultar em maiores desgastes.

Em relação à inspeção, a norma determina que a atividade deva ocorrer regularmente, de forma a manter o elemento livre de detritos. Em caso de manutenção do pavimento, asfáltico ou de concreto, não devem ser criados degraus e muito menos obstrução ou sobreposição das juntas. Por último, deve-se verificar a estanqueidade do dispositivo e a geração de ruídos durante a passagem de veículos.

\subsubsection{Métodos de inspeção}

De forma geral, a inspeção de juntas de dilatação é realizada de maneira visual. Como o tráfego não é interrompido, a observação por parte do inspetor fica limitada geralmente ao acostamento. Embora grande parte dos danos sejam detectáveis a olho nú, existem outras técnicas que podem ser utilizadas de maneira complementar (BRITO, LIMA, 2007). Dentre elas, destacam-se as técnicas auditivas e testes de impermeabilidade.

A principal e mais simples técnica auditiva não utiliza nenhum instrumento. Brito e Lima (2007) afirmam que quando um veículo passa sobre uma junta solta, gera-se um som metálico, que fica ainda mais evidente diante de veículos mais pesados. Outros métodos se baseiam na utilização de um martelo para, através da percussão, verificar a aderência e a existência de vazios, ou de um sonómetro diante de ruídos excessivos.

Por último destaca-se a verificação da estanqueidade da junta. Aplica-se uma determinada quantidade água sobre o elemento e verifica-se durante um determinado período, se há ou não a percolação do líquido para a parte inferior da estrutura (BRITO, LIMA, 2007).

\subsubsection{Manifestações patológicas mais comuns}

Durante a sua vida útil, as juntas de dilatação estão sujeitas a ações cíclicas e por isso, refletem muito bem a deterioração das OAEs. Quando uma das juntas apresenta algum sinal de mau funcionamento, é de extrema importância que se identifique e solucione o problema antes que o mesmo afete os demais elementos (FERREIRA, 2013).

Brito e Lima (2007) citam alguns dos danos mais comuns em juntas de dilatação: separação entre bordos da junta, defeitos de assentamento ou de concavidade, fissuração do pavimento paralelamente à junta, perdas do mastique de selagem e defeitos nos dispositivos de drenagem.

Ferreira (2013) atribui a fissuração aos processos de repavimentação sobre a junta, devido a menor elasticidade do material e também pela restrição a liberdade de movimentos. O autor também reforça que as juntas dificilmente garantem a estaqueidade e, por isso, são vulneráveis a percolação de água, expondo assim os aparelhos de apoio e os elementos de concreto. Ramos (2017) atribui a perda de impermeabilidade ao rompimento da fita de neoprene e cita como consequências a lixiviação dos elementos do cimento e os ataques por sulfato.

\subsubsection{Pontes semi-integrais e integrais}

As juntas de dilatação possuem um alto custo de implantação e manutenção, uma vez que representam foco histórico de problemas devido à frequente necessidade intervenções. Essa necessidade se dá em razão do desgaste contínuo, das cargas móveis cíclicas e das alterações de volume devido às variações de temperatura. Além do custo, outra dificuldade encontrada na manutenção das juntas é a necessidade de interrupção do tráfego (SOARES, 2011). 
Lima e Brito (2006) demonstraram o quanto o reparo das juntas de dilatação é significativo em relação aos demais gastos com as obras. Os autores evidenciaram que de 2003 a 2005 os gastos com a manutenção das juntas em algumas rodovias portuguesas representam entre $20 \%$ e $30 \%$ dos gastos totais com pontes, conforme Figura 2.

Por meio do Manual de Projetos de Obras de Arte Especiais (1996), o DNER chama atenção para as dificuldades advindas da utilização de juntas. De acordo com o manual, deve-se evitar o máximo que possível a utilização de juntas de dilatação em pontes e viadutos.

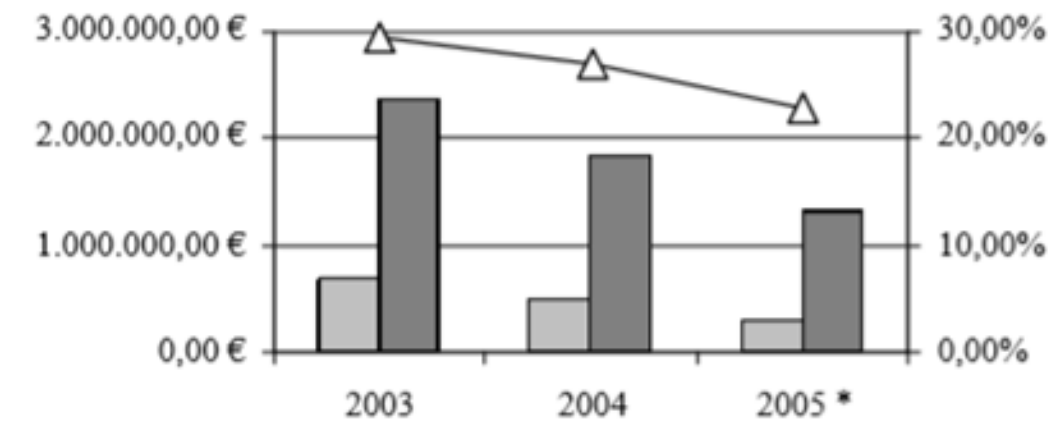

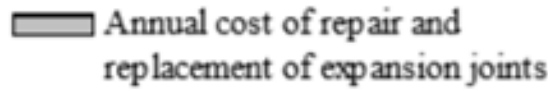

$\square$ Annual budget for bridge management

$\Delta-$ Percentage of costs with expansion joints

* Costs estimated based on the values obtained between January and August.

Figura 2: Custos envolvendo reparo/substituição das juntas de dilatção (LIMA, BRITO, 2006)

Soares (2011) cita que a adoção de lajes de continuidade tem sido utilizada no Brasil como uma alternativa de eliminação parcial das juntas. A eliminação completa ainda não é encontrada no Brasil, mas já é executada em países como Estados Unidos e Canadá, por meio das pontes integrais. O autor cita que a construção de pontes integrais nos últimos 30 anos tem gerado redução nos custos de construção e manutenção em longo prazo.

\subsection{Estudos de Caso}

\subsubsection{Ponte sobre o Rio São Francisco (BR-242, Bahia)}

Inserida na BR-242, no estado da Bahia, a Ponte sobre o Rio São Francisco é responsável por ligar os municípios de Ibotirama e Muquém de São Francisco, possuindo 963,00 m de extensão e 10,80 de largura. A obra possui 11 juntas de dilatação distribuídas ao longo de sua extensão. Tratam-se de juntas em perfil de elastômero comprimido classificadas por Lima e Brito (2009) como tipo 5.

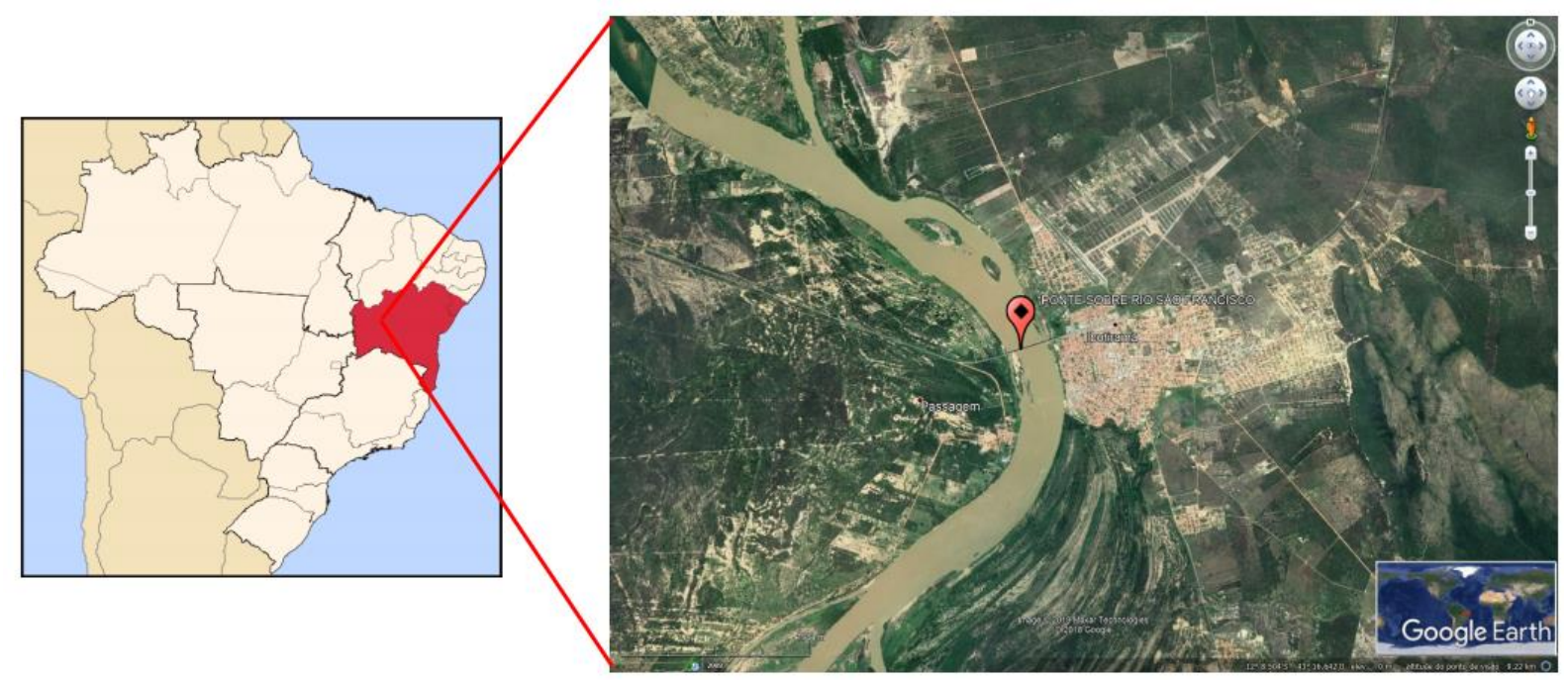

Figura 3: Localização da Ponte sobre o Rio São Francisco ( $12^{\circ} 10.744$ 'S, $\left.43^{\circ} 13.345^{\prime} \mathrm{O}\right)$.

Jahren e Miller (2014), descrevem que esse tipo de junta utiliza os elastômeros, geralmente de neoprene, como dispositivos de vedação, de forma a impedir a passagem de água através da separação. Os autores afirmam que a falha 
do selo não prejudica o tráfego ou mesmo o funcionamento da ponte, uma vez que não impede a movimentação da estrutura. Por outro lado, permite a percolação de água, assim como a passagem de produtos químicos e sais, podendo causar a deterioração da estrutura.

Conforme Figuras 4 e 5, percebe-se que o elastômero foi parcialmente expelido da junta de dilatação. Dessa maneira, a junta perdeu a estanqueidade, expondo a parte inferior da superestrutura e a mesoestrutura a percolação de águas pluviais. Verifica-se nas Figuras 6 e 7, que a percolação já atinge os elementos estruturais, como a laje, vigas, travessas e pilares, causando a deterioração do concreto.

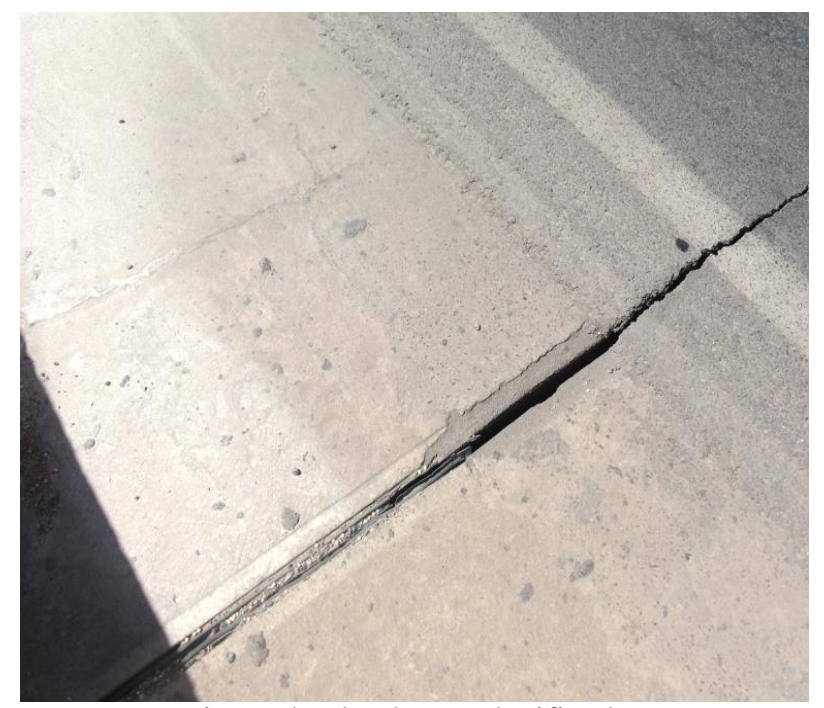

Figura 4: Elastômero danificado.

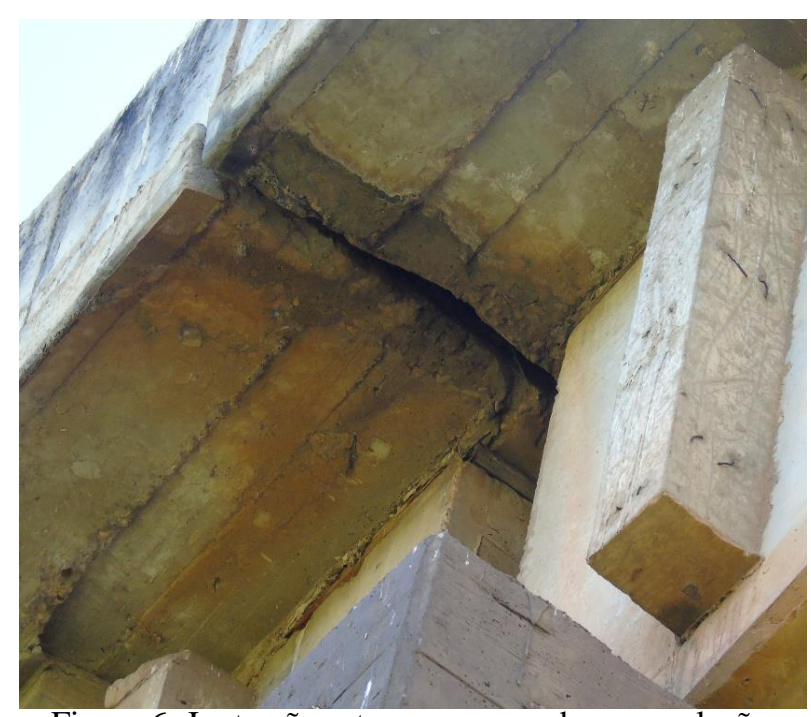

Figura 6: Junta não estanque causando a percolação de água.

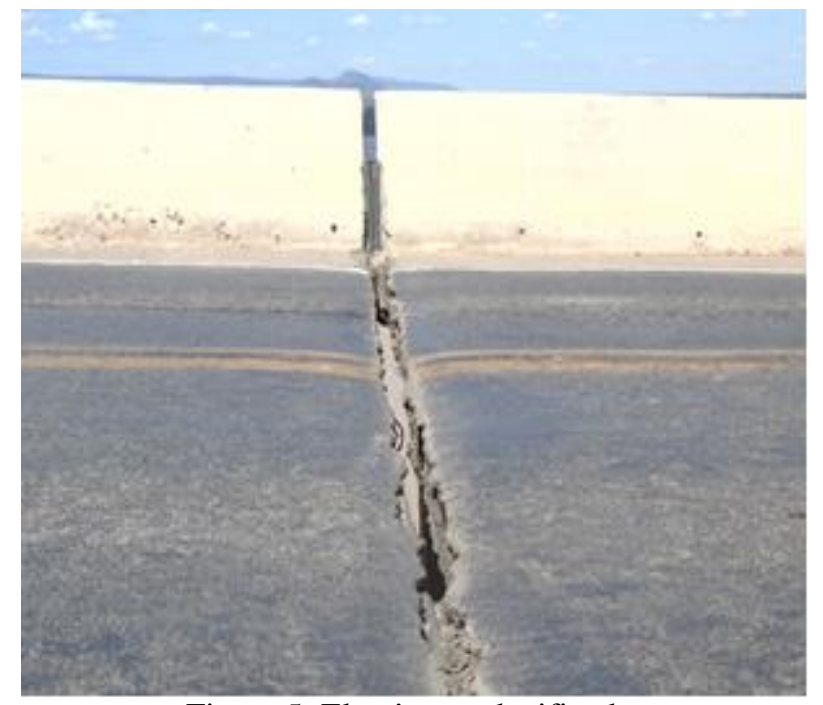

Figura 5: Elastômero danificado.

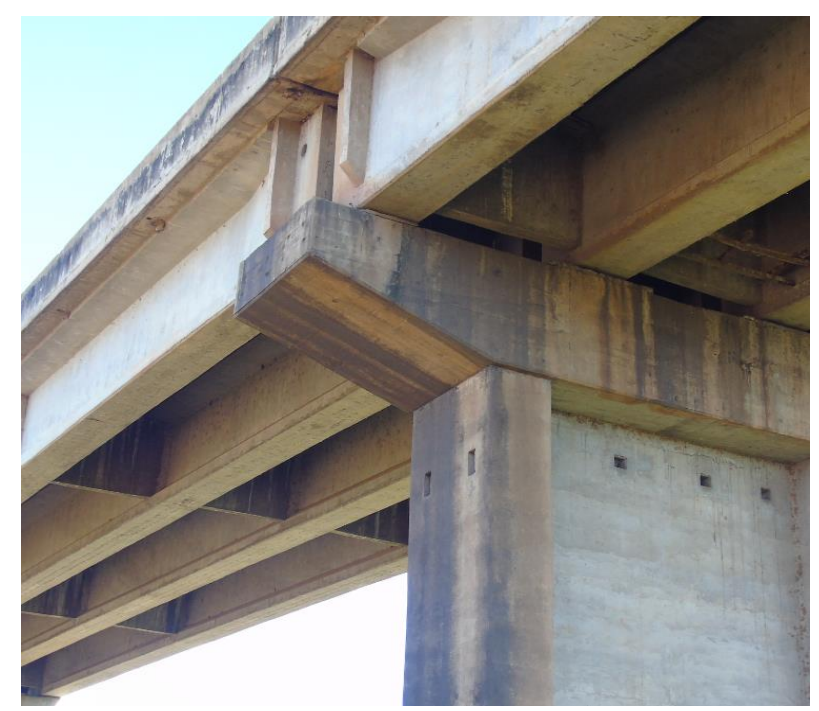

Figura 7: Junta não estanque causando a percolação de água

\subsubsection{Ponte sobre o Rio São Francisco (BR-110, Bahia)}

Localizada na divisa de Alagoas com a Bahia, a Ponte sobre o Rio São Francisco é uma ponte metálica que integra a BR-110. A obra, de 240,00 m de extensão e $10,00 \mathrm{~m}$ de largura, possui ao todo 5 juntas de dilatação. Dentre os dispositivos identificados, verificou-se que há juntas elastoméricas do tipo Jeene e juntas metálicas.

Analisando as inspeções realizadas em janeiro de 2014 e 2019, conforme Figura 9 e 10, respectivamente, verifica-se que houve o recapeamento do pavimento asfáltico, sobrepondo as juntas de dilatação. Pela Figura 10, é possível confirmar a presença da junta metálica. 


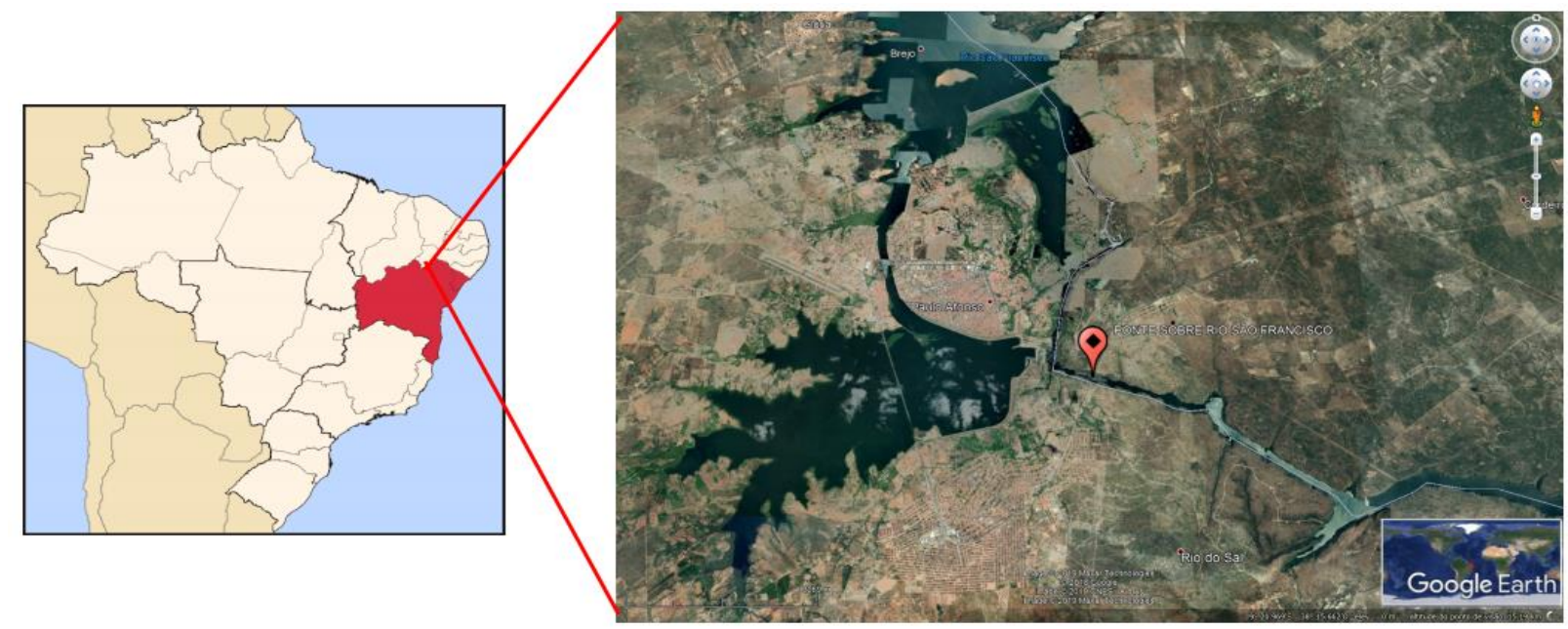

Figura 8: Localização da Ponte sobre o Rio São Francisco ( $\left.9^{\circ} 25.139^{\prime} \mathrm{S}, 38^{\circ} 11.851^{\prime} \mathrm{O}\right)$.

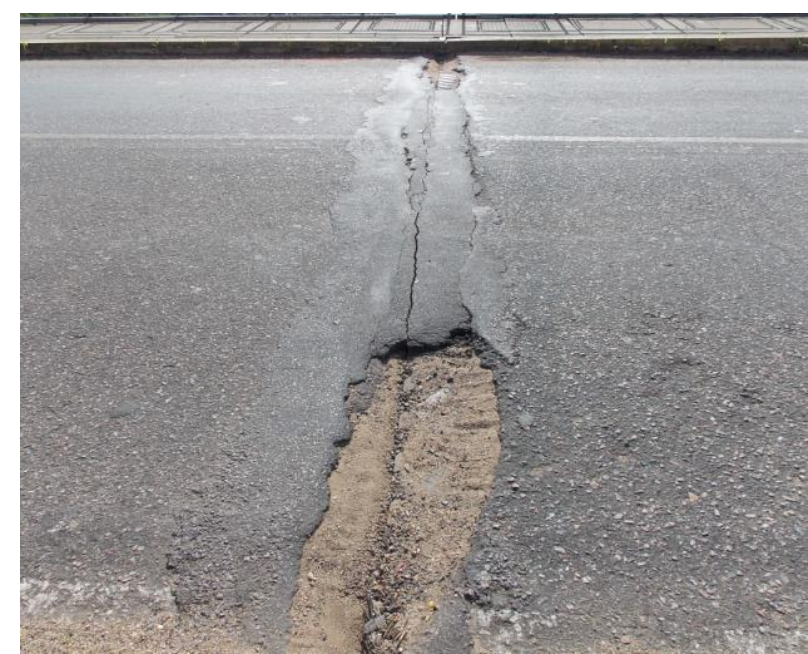

Figura 9: Junta de dilatação antes do recapeamento (2014).

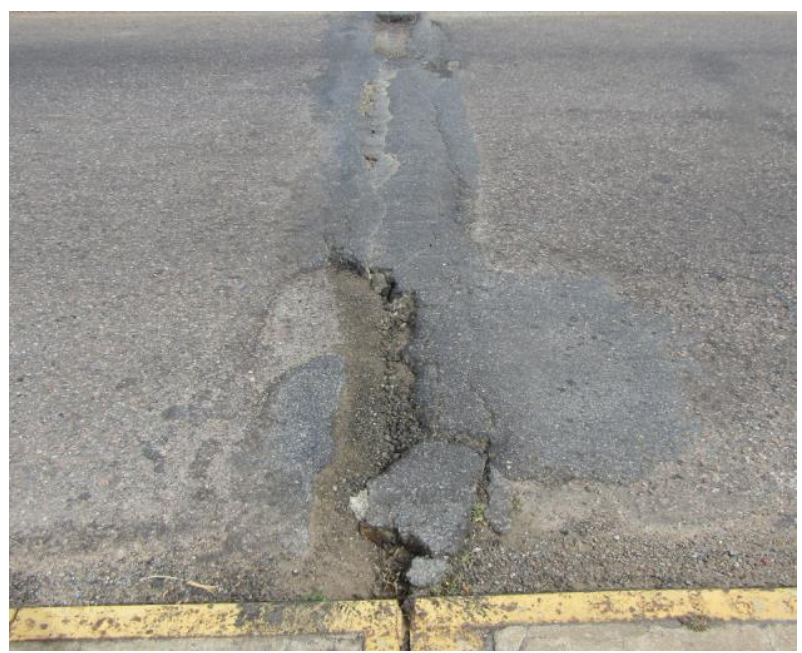

Figura 10: Junta de dilatação após o recapeamento (2019).

Ainda comparando as duas inspeções, verificou-se pela Figura 11, que em 2014 a junta de dilatação no centro da ponte já se encontrava danificada e permitindo a percolação de água. Entretanto, percebe-se com base na Figura 12, que mesmo após o recapeamento ser realizado, a junta continuou sem dispositivos de vedação. Dessa maneira, pode-se dizer que embora tenha ocorrido uma intervenção na obra, não foram tomados os devidos cuidados com o sistema de juntas.

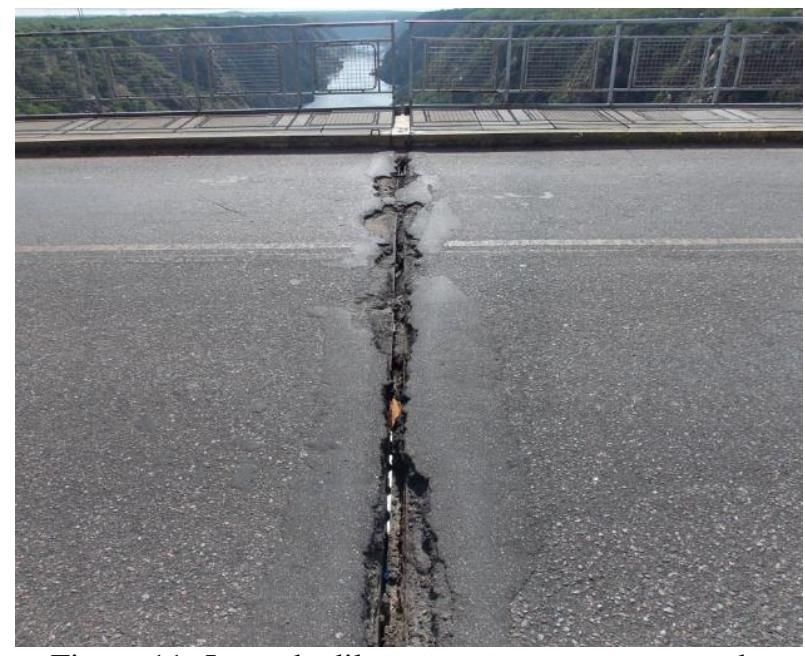

Figura 11: Junta de dilatação não estanque antes do recapeamento (2014).

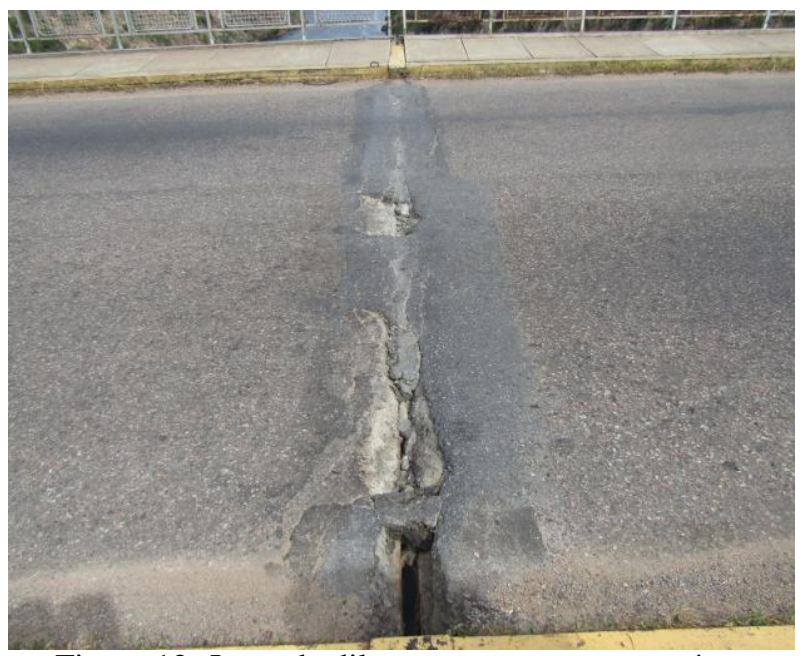

Figura 12: Junta de dilatação não estanque após o recapeamento (2019). 


\subsubsection{Ponte sobre o Rio Paranaíba}

Localizada na divisa dos estados de Minas Gerais e Goiás, a Ponte sobre o Rio Paranaíba possui 320,00 m de extensão e $10,00 \mathrm{~m}$ de largura. Ao todo identificou-se 5 juntas de dilatação, sendo que todas elas foram sobrepostas pelo recapeamento.

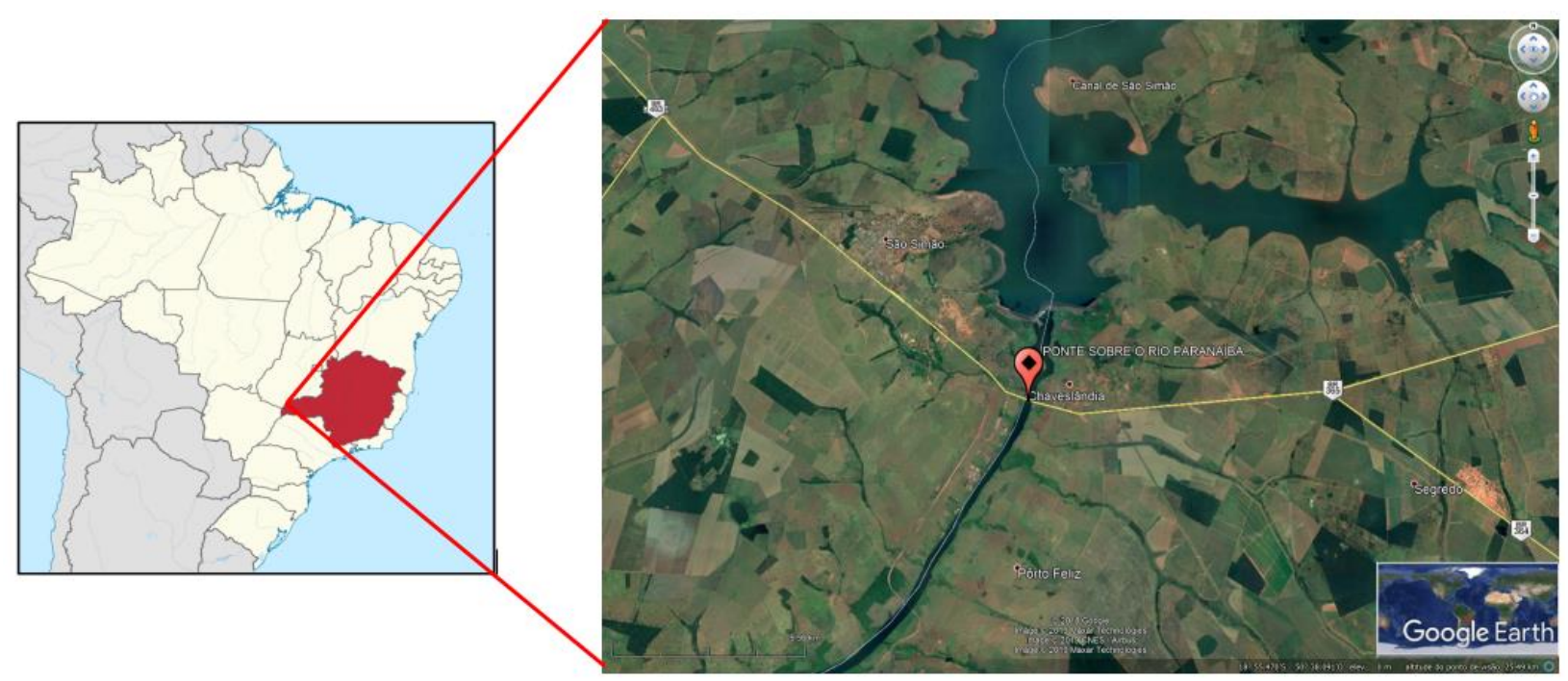

Figura 13: Localização sobre a Ponte sobre o Rio Paranaíba $\left(19^{\circ} 2.649\right.$ 'S, 50 30.040'O).

Verificou-se que se tratavam de juntas abertas, com cantoneiras metálicas para proteger a laje quanto ao tráfego de veículos. Além disso, não foi verificado nenhum dispositivo de vedação nas juntas abertas. Entretanto, não foi verificado in loco nenhum sinal de degradação do concreto devido à percolação de água através das juntas. Por fim, diante do tráfego de veículos pesados, notou-se uma elevada vibração e movimentação da ponte.

As juntas localizadas nos encontros apresentam fissuração do pavimento paralela aos elementos, conforme Figuras 14 e 15. As demais juntas localizadas ao longo da extensão da obra encontram-se em um estado de deterioração mais avançado, conforme Figura 16 e 17.

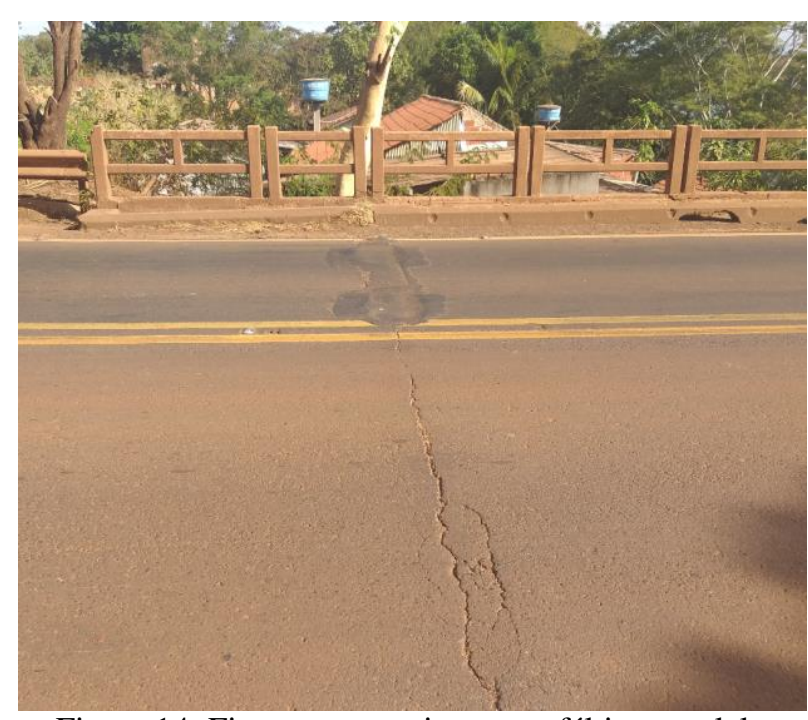

Figura 14: Fissuras no pavimento asfáltico paralelas à junta de dilatação.

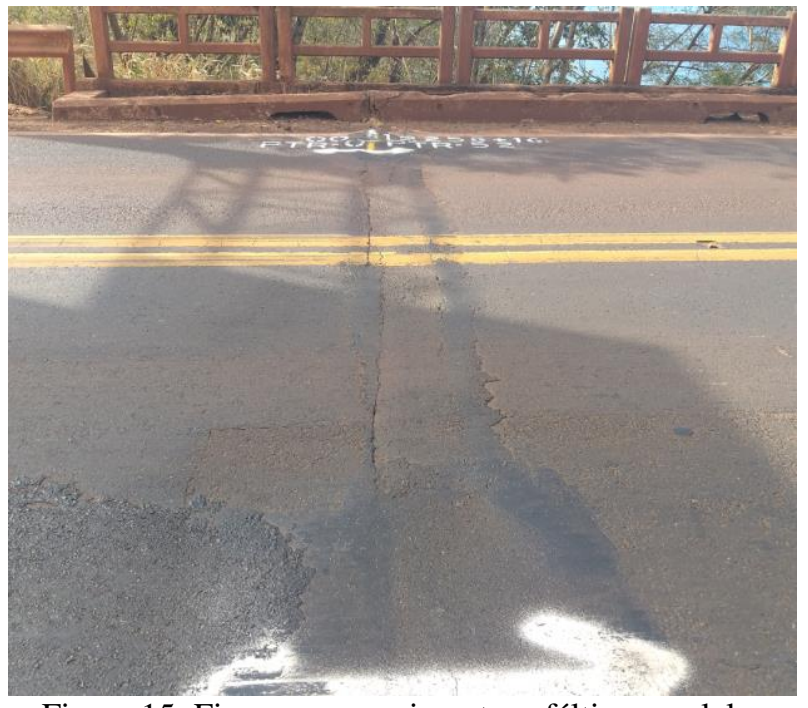

Figura 15: Fissuras no pavimento asfáltico paralelas à junta de dilatação. 


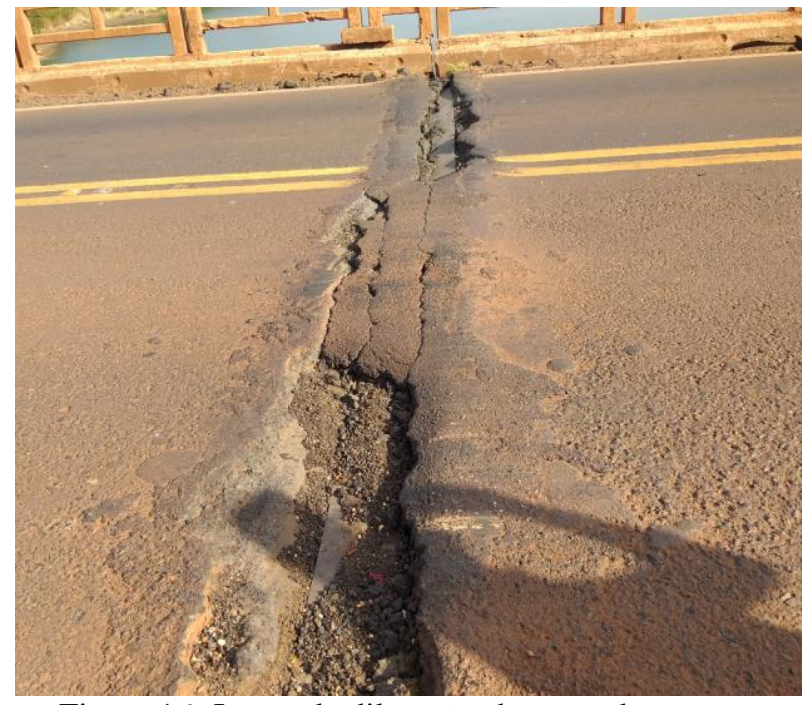

Figura 16: Juntas de dilatação abertas sobrepostas pelo pavimento asfáltico.

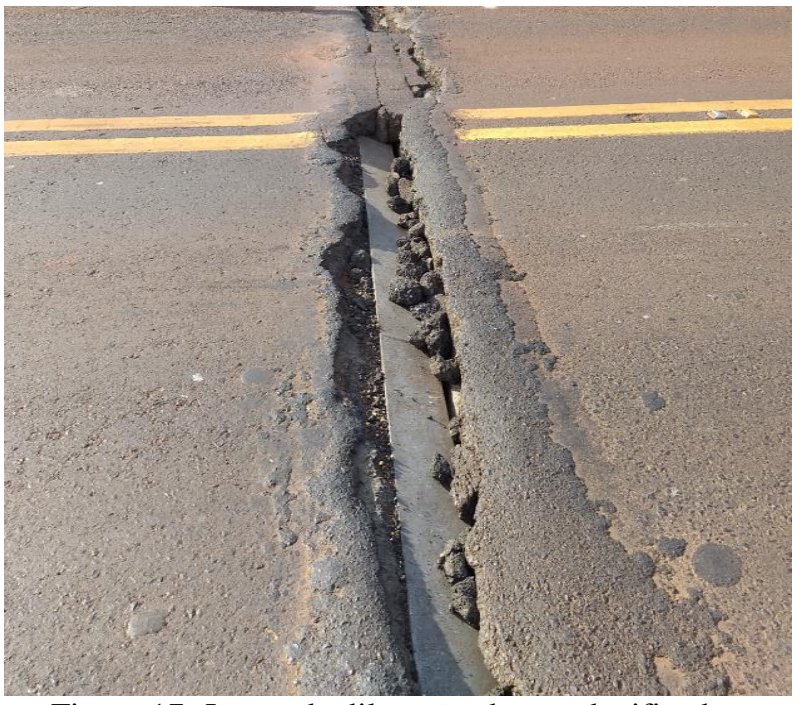

Figura 17: Juntas de dilatação abertas danificadas.

\section{CONSIDERAÇÕES FINAIS}

As juntas de dilatação representam intervalos abertos na estrutura das pontes e viadutos, de maneira a possibilitar a movimentação sem a transferência de esforços. Conforme necessidade de evitar a percolação de líquidos para a parte inferior das obras, as juntas são vedadas por elementos metálicos ou elásticos. Devido à vida útil curta desses dispositivos de vedação, as juntas de dilatação necessitam de frequente manutenção, respondendo por uma parcela significativa dos custos com intervenções gerais das obras.

A partir dos estudos de caso, foi possível perceber que a maior parte das manifestações patológicas em juntas de dilatação está associada à estanqueidade ou ao conforto e segurança dos usuários. Evidenciou-se também a prática inadequada de sobrepor as juntas durante o recapeamento das rodovias, falha comum na maior parte das rodovias brasileiras. Além disso, verificou-se por base de duas inspeções, com intervalo de 5 anos entre elas, que embora tenham ocorrido intervenções nos locais, nada foi feito em relação a juntas que já apresentavam problemas.

Dessa maneira, fica claro que existe um déficit de conhecimento técnico, por parte do mercado, a cerca das juntas de dilatação e que não é dada a devida importância por parte dos órgãos responsáveis. Indica-se a maior ocorrência de inspeções, atendendo as determinações normativas, e maiores investimentos quanto ao reparo dos elementos, uma vez que o seu mau funcionamento pode levar a maior degradação do restante da estrutura, ou a adequação de estruturas existentes a sistemas estruturais integrais.

\section{REFERÊNCIAS}

BRASIL. DEPARTAMENTO NACIONAL DE ESTRADAS DE RODAGEM. Diretoria de Desenvolvimento Tecnológico. Divisão de Capacitação Tecnológica. Manual de projeto de obras de arte especiais. Rio de Janeiro, 1996. 225p. (IPR. Publ., 698).

DNIT, 2006. NORMA DNIT 092/2006 - ES. Juntas de dilatação - Especificação de Serviço. Instituto de Pesquisas Rodoviárias. Departamento Nacional de Infraestrutura de Transportes. Ministério dos Transportes. Brasil.

FERREIRA, C. M. S. Tipologia, instalação, funcionamento e manutenção de diversos tipos de juntas de dilatação em Obras de Arte. Dissertação - ISEL. Lisboa, 2013.

JAHREN, C. T., MILlER, A. M. "Rapid Replacement of Bridge Deck Expansion Joints Study - Phase I" (2014). InTrans. Project Reports. 110. Disponível em: http://lib.dr.iastate.edu/intrans_reports/110, Acesso em: 26/11/2019.

LIMA, J. M. BRITO, J. Classificação das juntas de dilatação em obras de arte rodoviárias Portuguesas. Teoria e Prática na Engenharia Civil, n. 14, p. 31-41, Outubro, 2009. 


\section{CBPAT 2020 \\ CONGRESSO BRASILEIRO DE PATOLOGIA DAS CONSTRUÇÕES \\ DE 15 A 17 DE ABRIL | FORTALEZA - CE \\ ISBN 978-65-86819-05-2}

LIMA, J. M. BRITO, J. Inspecção e diagnóstico de juntas de dilatação em obras de arte rodoviárias. Engenharia Civil da Universidade de Minho, Nº 28, 2007.

Lima, J. \& Brito, Jorge. (2006). Road Bridge Expansion Joints: Existing Systems and Most Common Defects. 10.13140/RG.2.1.1898.8247.

MISTRY, V. C. 2005. “Integral Abutment and Jointless Bridges”. In: The 2005 FHWA Conference (IAJB 2005), Constructed Facilities Center, College of Engineering and Mineral Resources, West Virginia University Baltimore, Session 1, pp 3-11, Maryland, USA, March 16-18, 2005.

RAMOS, M. O. Estudo da implantação de juntas de dilatação em pontes e viadutos. Trabalho de concluso de curso - ULBRA. Palmas, 2017.

SOARES, R. W. Efeito da variação de temperatura em pontes integrais de concreto com fundações em estacas de aço. Projeto de Graduação - Universidade Federal do Rio de Janeiro. Rio de Janeiro, 2011. 